\title{
Kruno Pranjić
}

\section{DESET ZAPOVIJEDI \\ (Koje to nijesu?!)}

\section{TEN COMMANDMENTS \\ (not really?!)}

\section{Kolegi Damiru:}

Čestit hod $i$ kroz(a) "pe-m-ziju"

"Zapovijedi" jesu one starozavjetne što ih Mojsije (Mošè), židovski izbavitelj iz egipatskoga ropstva, vođa i zakonodavac, s narodom put putujući za "zemlju obećanu" Kanaan, na brdu Sinaju - svjedoči Stari zavjet - u susretu licem u lice s Višnjim bićem, od Njega dobio (tê narečene "Zapovijedi") uklesane u dvije ploče, i to do kojih trinaest stoljeća B. C. (before Christ $=$ prije Krista). Pripišemo li tima još 2009 "naših" godina A. D. (Annorum Domini = ljêta Gospodnjìh), već je tomu impresivnih do tridesetitriju stoljeća da se/otkako se i štuju i prestupljuju/krše zapisi o valjánu ponašanju spram Stvoritelju, a i bližnjima...

$\mathrm{Da}$ "Desetere zapovijedi" odista nijesu autoritarne, bespogovorno naredbodavne, kategorički da nijesu izričaji - dokazom je i to što izvorno nijesu odrješito u glagolskome modusu imperativa, "jerbo" klasični hebrejski toga (zapòvjednoga) načina prosto naprosto "nejmađaše", a i izvorna naslovna dvočlana sintagma glasi nenavadno: aserèt $=$ deset, hadiberòt $=$ pl. imenice riječ́; dakle: prijevodna bukvalna istovetnost. A i prvi prvcati biblijski prijevod, helenski, potječe od tzv. Septuaginte; povijesno pouzdano: priređivan je od $\leftarrow$ III. do $\rightarrow$ I. st. u Aleksandriji (Egipat) u sukcesiji Sedamdesetorice, prevodilaca (pokratom označen

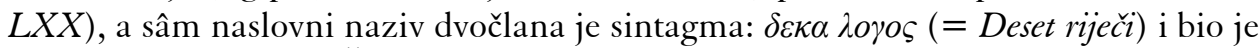
(prijevod) namijenjen Židovima koji više ne govorahu hebrejskoga.

Ogledat ćemo taj helenski prijevod 5-8. "zapovijedi"; dakako, nećemo ispisivati nepristupačan/nenavičan nam "alephbetski" hebrejski izvornik, ali hoćemo alfabetni prijevodan prijenos u helenski; i to dvostruko: alfabetno izvorno, pa abecedno transliterirano; naposljetku - usporedbē i kontrastacijē radi - u jedan od prijevoda u hrvatski, iz takozvane Zagrebačke Biblije, pod egidom dvojca kompetentnih bibliologa i prevoditelja: Dude fra Bonaventure i Fućka fra Jerka, a u izdanju "Stvarnosti" 1968 (!!), uza suptilan tandem stilizatora - partizanskoga pjesnika Jure Kaštelana \& enciklopedijskoga poliglotskog znalca Josipa Tabaka; navod je iz Petoknjižja, Knjige Izlaska: 


\begin{tabular}{|c|c|c|c|}
\hline 0.13 & 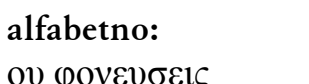 & $\begin{array}{l}\text { transliterirano: } \\
\text { ou foneúseis }\end{array}$ & $\begin{array}{l}\text { prevedeno (u hrvatski): } \\
\text { Ne ubii! }\end{array}$ \\
\hline 14 & 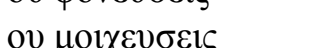 & ou moikheúseis & Ne učini preljuba! \\
\hline 15 & ov $\kappa \lambda \varepsilon \psi \varepsilon i \varsigma$ & ou klépseis & Ne ukradi! \\
\hline 16 & ov & ou & Ne svjedoči \\
\hline & $\psi \varepsilon v \delta о \mu \alpha \rho \tau v \rho \eta \sigma \varepsilon \imath \varsigma$ & pseudomartyrēseis & \\
\hline & $\kappa \alpha \tau \alpha \tau$ ov $\pi \lambda \eta \sigma i о \nu$ & kata tou plēsion & lažno na \\
\hline & $\begin{array}{l}\text { боv } \mu \alpha \rho \tau v \rho i \alpha v \\
\psi \varepsilon v \delta \eta\end{array}$ & $\begin{array}{l}\text { sou martyrian } \\
\text { pseudē }\end{array}$ & bližnjega svoga! \\
\hline
\end{tabular}

U latinskome prijevodu obaju zavjeta - Vulgati, što ga je iz izvornih jezika (hebrejskoga i aramejskoga te helenskoga) "na pučku" latinštinu izveo sv. Jeronim (Hieronymus Sophronius Eusebio, 347-420) rodom iz "Stridona", nelocirana lokaliteta u Dalmaciji; slijed je ovaj:

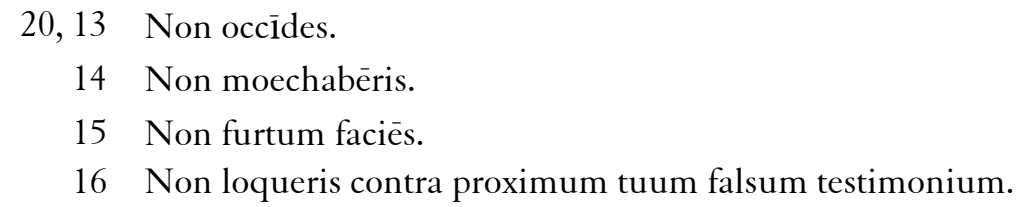

Primijetiti je da su u obojim prijevodima (grčkome i latinskom) glagolska vremena u indikativu futura, tj. u vremenu budućem. Znači: bio je poštovan gramatički oblik izvornika. Inače, X Zapovijedi on (Jeronim) nazivlje latiniziranim helenizmom s pomoću sufiksalnog morfema -us: Decalogus!

U ćirilometodskoj baštini na tlu Hrvatske reprezentativan je glagoljički ulomak s početka XV. st. (1403/04) u Hrvojevu misalu, gdje su ovakvi dvoji prezenti iz Izlaska (Exodus):

\section{Ne ubiješi! \\ 14 Ne ukradeši!}

Ali, premda su to dva gramatička prezenta, s obzirom na to da se aspekatski perfektivna (vidom trenutna) sintaktička im je funkcija budućnosna (futurska), a: nota bene - mogli su - teoretski - respektivni glagoli biti i u imperativu (ne ubii, ne ukradi), ali bi bili nepodudarni sa svojim futurskim predlošcima - helenskim i latinskim...

Sad, kronološki, bio bi rêd na čuvènu disidentu od rimokatoličja: Martin Luther (1483-1546) zgotovio je pun prijevod obaju zavjeta 1534. na njemački (i dan-danas aktualan kao uzor visoke stilizacije; svoju prijevodnu meštriju nazivlje - Die heilige zehn Gebote $=$ Deset svetih naloga $\neq$ Befehle $=$ zapovijédī, što bi imalo izravno zapòvjedne/militarne konotacije. Onē već oglèdāvānē četiri pozicije 
kompozita Dekaloga Luther rješava negiranim prezentom glagola nepotpuna značenja: sollen plus infinitivom respektivnoga glagola; opet:

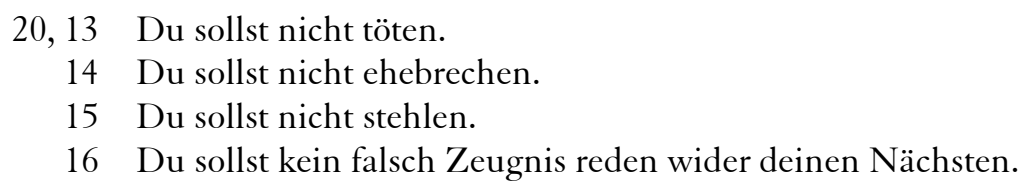
Potencijalnih imperativa Töte nicht, ili Brich die Ehe nicht - ni da bi (mašio se)...
Poprilično kasnije, 1611, anglo-irsko-škotska Authorized king James Version, tj. prijevodna inačica pod pokroviteljstvom kralja Jakova I. ima analogan postupak s pomoćnim glagolom shall za izravnu tvorbu niječnoga perifrastičnoga futura:

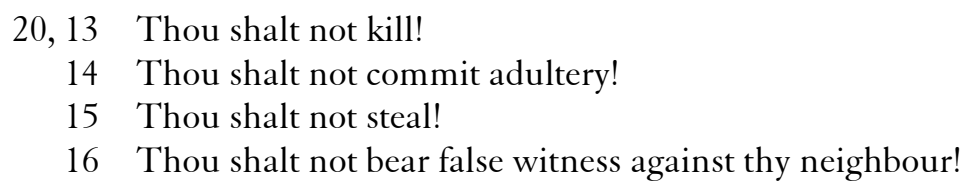

Kronološki, na redu je A. D. (= Annus Domini) 1625: VERSIO ILLYRICA SELECTA, seu declaratio Vulgate editionis latinae, Bartholomei Cassij Curictensis e Societate Iesu Professi, ac sacerdotis theologi, ex mandato Sacre Congregationis de propaganda fide, Anno 1625, tj. ilirska prijevodna inačica ili razlaganje Vulgate latinskoga izdanja... Bartola Kašića [Pag 1575 - Rim 1650] po narudžbi Svete udruge za promidžbu vjere, god. 1625. Komentar: otužna, huda sudba - Bartol snuje, Kongregacija odlučuje, predestinacijski... mâran Kašić nije doživio knjižne promocije (premda s vrha crkòvné hijerarhije nàrūčenē) - štokavsko-ikavska inačica Vulgate bila je naručena-prešućena, neznano rašta i čemu... Dogodila joj se zla kob vješto sordinirana urnebesa. Solanelno objavljena je 1999. (tekar - dakle - rečenoga godišta) viribus unitis četiriju gradova: Paderborn-München-Wien-Zürich, "kasnim paljenjem" i krhkom utjehom, kao: bolje ikad nego nikad...

Ipak, evo ogledne verzije, sad u Pismu zakonoponavljen'ja iliti Deutoronomiju:

Nećeš ubiti.

Nećeš bludnovati.

I lupeštinu nećeš učiniti.

Nećeš govoriti suproć iskarnjemu tvomu krivo svidočanstvo.

Ma: koje li "šesne" ikavske štokavštine što je - avaj! - "falila" biti općehrvatskom razvojnom koinê pred gotovo četirista ljêtā(h)! kapitalan prijevod ovaj, prikraćen za život, ostaje pogrebni torzo, kulturnopovijesni hiatus... 
Da sad zeru zirnemo u do tri suvremene "bjelosvjetske" verzije već nam znanih istih mjesta? Pa evo:

LA BIBBIA in lingua corrente (tal. Biblija suvremenim jezikom); Esodo (= Izlazak), Il dieci comandementi:

20, 13 Non uccidere.

14 Non commettere adulterio.

15 Non rubare.

16 Non testimoniare il falso contro nessuno.

Primijetiti je: Deset zapovijedi i svačetiri infinitiva!

Isto mjesto: Десять заповедей, Библия, книги священого писания Ветхого и Нового завета, канонические, Американское библейское общество, Нью Иорк:

\section{izvorno (ćirilicom)}

20, 13 Не убивай.

14 Не прелюбодействуй.

15 Не кради.

16 Не произноси ложного свидельства на ближнего твоего. transliterirano (latinicom):

Ne ubivaj.

Ne preljubodejstvuj.

Ne kradi.

Ne proiznosi ložnogo

svidel'stva na bližnego tvoego.

Primijetiti je naslov: Deset zapovijedi i svačetiri puta zapovjedni način (imperativ)!

$*$

$* *$

Najzad: the last but not the least, dapače - navrhunit ću ove drobne (= sićane) ilustracije najdražim oprimjeravanjem višejezičnih prijevoda unikatnim prevoditeljem u svijetu, u bijelome, André Chouraquijem koji je sam-samcijat i jedini-jedincat, opet: na svijetu, zanosno preveo svetri sakralne knjige monoteizma:

židovskoga (Stari zavjet) s hebrejskoga, izvorna

kršćanskoga (Novi zavjet) s helenskoga (grčkog), izvorna

islamskoga (Kur'an) s arapskoga, izvorna

u sofisticiran standardni francuski. Pivot-prijevodni uzorci isti su kao i predšasni: 5-8. "zapovijed", ovaj put pod novim podnaslovom Dix paroles $=$ Deset besjeda (umjesto Dix commendements = Deset zapovijedi), u: LA BIBLE traduite et présentée par André Chouraqui, Desclée de Brouwer 1986:

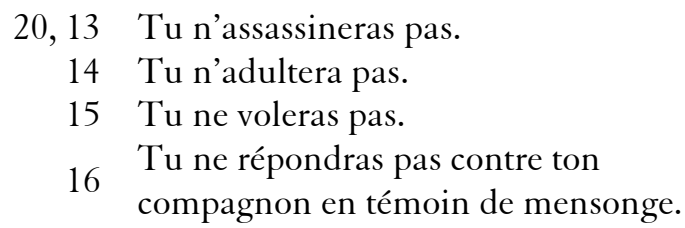


Svođenje imenovanja glagolskih oblika i etimona u poliglotskoj dekaloškoj revijalizaciji nije tek puka statistička enumeracija, nego implicitna egzegeza/hermeneutika istih: futur/infinitiv // riječ/besjeda nasljeduju kriterij zvan liberum arbitrium, tj. slobodan izbor izvan ikakve prinude (bilo unutarnje ili vanjske) dok suproćan (usp. u Kašića), tj. suprotan kriterij zvan servum arbitrium, tj. hijerarhijski subordiriran stav imperativom i zapovijeđu isključuje slobodu i djelovanja i nedjelovanja, ništi integritet subjekta oduzimanjem šanse da bude odgovoran te da tako - obezvoljen i sapet - mórati môrā ili moradne morati?!

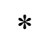

$* *$

Intermezzo \& moderato cantabile \& maestoso... ovdje ću, potpisani, popostati eda bih udahnuo te da odahnem naklonivši se pred citatom:

Pavlova poslanica Rimljanima ide u najznačajnija djela svjetske književnosti [sic!] koja se bave podjednako problemom čovjekove bijede i čovjekova dostojanstva, (Bonaventura Duda, "Uvod u pojedine knjige Novoga zavjeta", u: Novi zavjet, s grčkoga izvornika preveli B. Duda \& J. Fućak, Kršćanska sadašnjost, Zagreb 1993, str. 751).

A prijevod, u harmoniji subraće Bonaventure i Jerka, nek govori sâm od sebe (uz gorušičine pokrate (i isticanja):

$12^{3} \ldots$ ne precjenjujte se više no što se treba cijeniti, nego cijenite se razumno... ${ }^{6}$ Dare pak imamo različite po milosti koja nam je dana: je li to prorokovanje - neka je primjereno vjeri; ${ }^{7}$ je li služenje - neka je u služenju; je li poučavanje - u poučavanju; ${ }^{8}$ je li hrabrenje - u hrabrenju; tko dijeli, neka je darežljiv; tko je predstojnik - revan; tko iskazuje milosrđe - radostan! ${ }^{9}$ Ljubav nehinjena! Zazirite oda zla, prianjajte uz dobro! ${ }^{10}$ Srdačno se ljubite pravim bratoljubljem! Pretječite jedni druge poštovanjem! ${ }^{11} \mathrm{U}$ revnosti budite hitri, u duhu gorljivi... ${ }^{14}$ Blagoslivljajte svoje progonitelje, blagoslivljajte, a ne proklinjite! ... ${ }^{16} \ldots$ Neka vas ne zanosi što je visoko, nego privlači što je ponizno. Ne umišljajte si da ste mudri! ${ }^{17}$ Nikome zlo za zlo ne vraćajte... ${ }^{18} \mathrm{Ako}$ je moguće, koliko je do vas, u miru budite sa svim ljudima! ${ }^{20}$ Ako je gladan neprijatelj tvoj, nahrani ga, i ako je žedan, napoj ga! ... ${ }^{21} \mathrm{Ne}$ daj se pobijediti zlom, nego dobrim svladavaj zlo.

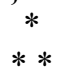

Univerzalnost/mundijalnost/globalnost/svesvjetskost individualne $i$ socijalne etike $u$ do osam ponajuecíh sujetskih religija...

Nije potreba sinkretizmom ih "miksati; posve je dovoljno sinergijom ih plemeniti: etiku Desetorih besjeda (Dekaloga) mahom dijele: i bahaisti, i brahmanisti, i budisti, i konfucijevci, i šintoisti, i sikhi, i sljedbenici Zaratustre", jer su otkrili zajedničku si spoznaju o temeljnom jedinstvu ljudske obitelji od Arktika do Antarktika, od Orijenta do Okcidenta... Afrički animizam čak da nas je, zemljane, kadar podučiti poštivanju života i svega postojećega; sibirski i šamanizam američkih 
Indijanaca da nam može otkriti neslućene mogućnosti naše psihe; urođenički totemizam (opet: čak) da može konkretizirati savez sa životinjskim svijetom kojega temelji da su dáni u Bibliji, al' čiju praktičnu primjenu tzv. "narodi Knjige" (Tore, Evanđelja i Kur'ana) uglavnom da zanemaruju.

Sad, evanđelist Matej, oko A. D. 60. sroči svoje Evanđelje (prvotno na aramejskome). Prevoditeljski tandem Duda/Fućak, nazvavši to Zlatnim pravilom, prevedoše i ovo ćudoredno pravilo iz Isusove Besjede na gori:

$7,{ }^{12}$ Sve, dakle, što želite da ljudi vama čine, činite i vi njima!

Sad, tko nabàsā na World Bible, na ma koje od brojnih američkih i kanadskih izdanja Colonial Press Inc. iz protekloga (XX) stoljeća, na str. 8. uočit će:

What you do not want done to yourself, do not do to others.

(= Što ne želite da vama bude učinjeno, ne činite drugima.)

Doista, ovaj dragulj od potonje sentence vjerodostojno je datiran u doba od pred kojih pet stoljeća prije Krista kao modelno naslijeđe konfucijanskih sakralnih spisa svjedočeći o nedjeljivosti univerzalnoga zajedništva glédē na kapitalne etičke spoznaje $\mathrm{i}$ orijentire u ljudskome besprijekornomu ponašanju, sentence porukonosno srodne do istosti, stilizacijski tek oprečne: novovjeka (Kristova) izrekom potvrdnom, starovjeka (Konfucijeva) niječnom.

Škrto ću još naredati pokoju pregršt primjera duhovnih vrednota proverbijalno sintetiziranih u mudrosnoj baštini dalekoistočnih religija staroga vijeka:

\section{HINDUIZAM/BRAHMANIZAM}

Sakralni tekstovi Upanišade (800-600 B. C.) sljednice su gotovo milenijski starijih religijsko-filozofijskih rasprava, Veda. Primjerice:

Obuzdaj se, darivaj, budi milosrdan!

Kako tko djeluje, takav će i biti. Čestit se postaje dobrim djelima, a opak zlima. Kako god što da učini, tako će i požnjeti.

Dobro je jedno, ugoda nešto drugo. Lako s onim što se drži dobra; tko odabire ugodu, ne postiže svoju svrhu. 


\section{ZARATUŠTRIZAM}

Zaratuštra (660-583 B. C.) iranski (perzijski) je propovjednik i filozof; tek dvije sentence iz opusa:

Tko drugomu u oskudici pomaže, sjedinjuje se s Ahurom-Mazdom [= glavnim božanstvom].

Bio ti gospodar čemu neznatnu ili pogolemu - iskazuj naklonost ka vrlini!

\section{DAOIZAM (kineski: $d a o=$ pût)}

Osnivač mu Lao-ce (604-531 B. C.) kineski moralist i filozof; iz riznice njegovih izreka:

Onomu tko svijet ljubi kao što ljubi vlastito tijelo mogu se povjeriti svjetovni posli.

Uzvrati ljubavlju na silnu mržnju!

Sve što jest ima dao u sebi i nastavlja ga bez kraja i konca. Beskrajna ljubav mudračeva spram svojih bližnjih temeljena je na istome počelu. Čestiti se utječe sporazumijevanju.

Spram dobroga ponašam se dobrohotno. Spram vjernika s povjerenjem. Spram bezvjernika (isto) s povjerenjem.

\section{BUDIZAM}

Osnivač mu Gautama Siddharta, Buddha (563-483 B. C.), "prosvijetljeni", indijski filozof i učitelj; nauk: pravičan život, ispravno mišljenje i samoodricanje duši omogućuje dosegnuti NIRVANU = božansko stanje oslobođeno zemnih patnji i želja:

Mržnja nikad ne ugašnjuje. Mržnja prestaje ljubavlju. Prastaro pravilo! Osvojiti sebe samo, bolje je nego vascijeli svijet.

Onomu u kom se nastanila ljubav, svi na svijetu su braća.

Nek čovjek gnjev prevlada ljubavlju, zlo dobrim; nek lakomost suzbije velikodušnošću, laž istinom.

\section{KONFUCIJANIZAM}

Kung-fu-ce, Konfucije (557-479 B. C.) kineski je filozof i učitelj; etički mu nauk naglašuje odanost roditeljima, obitelji, prijateljima, štovanje predaka te nasljedovanje pravičnosti i miroljubivosti. Evo još pokoja sentenca poslična naboja:

Voli sve ljude! Upoznaj sve ljude!

Pravičnošću uzvrati na nepravdu, ljubaznošću na ljubaznost.

Mudrost, dobrohotnost i odvažnost - odreda su to svesvjetske vrline. 
I još zeru o suprijevodu s Jadrankom Brnčić:

André Chouraqui

Deset zapovijedi danas

Deset besjeda za pomirenje čovjeka s ljudskošću

Konzor, Zagreb 2005.

(André Chouraqui, Les dix Commandements aujourd'hui. Dix Paroles pour réconcilier l'Homme avec l'humain, Robert Laffont, Paris 2000)

Tko posegne za štivom Chouraquijevih prijevoda i komentara u potrazi za globalnom etikom, po njemu jedino kadrom osigurati svesvjetski mir i "pomirenje čovjeka s ljudskošću" - neće biti uskraćen...

Teksturna kompozicija ima muzikološku formu zvanu rondo: svaka od deset zapovijedi/besjeda ima komentare, kontrastivno-komparativne, s ovim odsječcima: 1. u judaizmu; 2. u kršćanstvu; 3. u islamu; 4. drugdje u svijetu i 5. u globalnoj etici temeljenoj na deseterim Besjedama kao ljudskim dužnostima, i to drevnim već 3300 godina naspram "Univerzalnoj deklaraciji o pravima čovjeka" iz 1948.

U svojoj knjizi Chouraqui promatra jednu za drugom Deset zapovijedi u svima trima monoteističkim vjeroispovijestima (judaizmu, kršćanstvu i islamu) sve do u naše dane. Iz poglavlja u poglavlje, vodeći računa o evoluciji običaja, društva, znanosti i tehnike, autor nam nudi nov pogled na primjenu i kršenje svake od Deset zapovijedi. Deset zapovijedi/besjedâ bjehu i jesu prva prvcata, a i jedina jedincata Deklaracija o dužnostima čovjeka. Kakve su to zapovijedi? Što su one značile u Mojsijevo doba? Koje se sve religije na njih pozivlju? Imaju li one kakve vrijednosti i za laike? Što one znače nama, današnjima? - samo su neka od pitanja na koja odgovara André Chouraqui. Ustvrđuje ponajprije da Dekalog nikad nije bio uistinu primijenjen. Kuda i kamo god svrtali pogled, te zapovijedi ljudi krše, ljudi sa svih strana - židovi, kršćani, muslimani, laici i drugi - bilo to zbog duha sustava ili nedostatka logike, zbog lijenosti ili puke ljudske gramzive sklonosti kratkovidim i sebičnim užicima. Tu i tamo zataškavane, kadšto (čak!) patvorene, čas strogo doslovno shvaćene, čas relativizirane - Deset "zapovijedi" bivaju tako besjedama koje nam je preotkrivati.

Chouraqui spominje tri povijesne deklaracije o pravima čovjeka: 1 . iz vremena američke revolucije (1776) koja je bila obilježila početak sveopćeg priznanja ljudskih prava. Za ovom uskoro je slijedila Deklaracija o pravima čovjeka $i$ gradanina iz Francuske revolucije (1789); Ujedinjene nacije proglasile su Univerzalnu deklaraciju o pravima čovjeka u Parizu (1948). Deklaracije govore o pravima, o dužnostima govori - Dekalog. A "Svjetski parlament religija", pod predsjedavanjem švicarskoga teologa njemačkoga jezika Hansa Künga, osudio je (1993) siromaštvo i zlouporabu koje da iscrpljuju naš planet (Zemlju) i ugrožavaju ga agonijom u pomanjkanju Globalne etike, te pozvao čovječanstvo da ju, tu etiku, prizna te primijeni njezina načela - etiku Deseterih Besjeda (tj. Dekaloga). 
U godini pojave Chouraquijeve kapitalne knjige (2000) UN i UNESCO objaviše manifest koji cio svijet pozivlje da se pridruži međunarodnom pokretu za kulturu mira i nenasilja. Godina 2000. imala je biti nadahnuće, novi kôd u preobrazbi sveukupnosti rata i nasilja u kulturu mira i nenasilja. Obraća se osobito mladima i budućim naraštajima... pozivom da se svi i svuda zauzimamo:

- za poštivanje života:

- za odbacivanje nasilja: fizičkoga, seksualnoga, psihološkoga, ekonomskoga i socijalnoga;

- za njegovanje velikodušnosti;

- za slušanje i dijalog da bismo se razumjeli... ne popuštajući fanatizmu, kleveti i odbacivanju drugoga, drugosti i različitosti...

- za očuvanje planeta i odgovornu konzumaciju prirodnih mu izvora;

- za ponovno iskazivanje "solidarnošći" uz puno dioništvo žénā...

\section{Zadaća obrazovanja}

Škole svih razina imaju svoj dio odgovornosti u zatvaranju duhova. Zahtjev za otvaranjem, dakle, hitniji je za sve one koji se brinu za budućnost svijeta, posebice za odgajatelje, bili oni vjernici ili laici. U laičkim školama sustavno bi se morale učiti komparativne religije. S druge strane, religijske škole moraju bdjeti nad tim da njihov duhovni odgoj ne bude takav da se o vlastitoj religiji govori kao da je jedina i najbolja na svijetu. Deset zapovijedi pripadaju cijelom čovječanstvu. Učenici imaju pravo to znati, a učitelji su dužni podučavati na koji način su te zapovijedi razumjele i živjele različite kulture kroz stoljeća u različitim religijama, vjeroispovijestima i različitim zajednicama.

Nije riječ o tome da se nametne religijski odgoj u laičkim školama, još manje o tome da se one pretvore u religijske škole, nego o tome da se na svim razinama školskih programa uvede učenje o velikim religijama cijelog svijeta tako da se učenicima pruži ključ za bolje razumijevanje bližnjeg i samih sebe. Odgojittelji $i$ učitelji morali bi prijeći granice koje su stoljećima podizane među kulturama Orijenta $i$ Zapada. Stavljanje religija i kultura u sinergiju olakšat će vršenje Deset zapovijedi/Besjeda koje su odveć često zaboravljane. Rascvat religija koje će ih podučavati bit će na dobrobit cijelog čovječanstva. Savez nad savezima i teologije sestrinskih religija, odveć dugo neprijateljice, omogućit će nam da se napokon i konačno otvorimo za zbilju svijeta, za znanstvena i tehnička otkrića koja svakodnevno modificiraju naš pogled na zbilje univerzuma.

Da bi se utopija sveopćeg mira preobrazila u pobjedničku stvarnost, nužno je odgajati ljude i pripremiti ih da se vrate u Eden iz kojeg su se sami izagnali. Svaki čovjek, odakle da bio, sutra će morati baciti nov pogled na stvarnost; zato mora pobijediti svoje tisućgodišnje strahove, nagone, želje i navike. Deset Besjeda pokazuju mu put.

Naše dojučerašnje XX. stoljeće, okrvavljeno onòlikim masakrima i (raz)bojištima, ljudskim "kanàrama" (klaonicama), dočekalo je ostvarenje nekòlikih 
utopija koje čovječanstvo dotada nije moglo pojmiti. Kročili smo nogom na Mjesec, prokrstarili smo nebo i zemlju ter prodrli u najneproničnije tajne atoma i gena: nisu li sve to utopije koje je, međutim, ljudski genij već ostvario? U utopiju mira i ljubavi vjerovahu i za nju se, svatko na svoj način, u dvadesetom stoljeću zauzimahu: Mahatma Gandhi, Martin Luther King, Lanza del Vasto, Majka Tereza... bogme i A. Chouraqui s intimusom Ivanom Pavlom II, rimskim papom!

Ovdje je prava zgoda pozvati se na dva sunarodnjaka nam: prvi je jedini "našijenac" dobitnik Nobelove nagrade za književnost (1961) - Ivo Andrić, "istinabog" agnostik, ali izrijekom u jednoj svojoj čuvenoj refleksiji (objelodanjenoj postumno) baš na "liniji" globalne (dekaloške) etike, kad reče: ... da samo kroz drugoga možemo potpuno osjetiti ljepotu i veličinu života koji nam je dat, koji je u nama $i$ oko nas... A Andrić nam, ovim svojim zagovorom ljekovitosti i smislenosti drugosti i različitosti, nema dvojbe, nije "suprotiva" etici volj' nam rijet' "globalnoj" (univerzalnoj/mundijalnoj/svesvjetskoj/vaseljenskoj) dekaloškoj - inclusive (= uključivo)...

\section{Identitet, i to: raskamenjen?}

Identitet: potreba za pripadnošću ili na pripadnost prinuda? Identitet zavičajni, obiteljski, lokalni, regionalni, rasni, rodni (spolni), plemenski/etnički, jezični, kulturalni, narodnosni (nacionalni), akulturacijski, klanski, klupski, sindikalni, stranački, navijački (fanovski), profesionalni - monistički ili pluralni... Ima li vrijednosne hijerarhičnosti među njima ili pak valjanosne diskriminacije? Filozofijski: identitet li je determinističan za svojega nosioca bez slobodne volje, ili je indeterminističan uza slobodu volje? Statičan li je ili dinamičan? Petrificirana konstanta ili mutacijska varijabla?

Napokon: religijski (vjerski) identitet kao garant za blaženu onostranost?

U nobelovčevoj, Andrićevoj ("fra" Ivinoj?!) priči Proba (iz 1954!!) na sretnu varijantu raskamenjene religijske pripadnosti nabasao je, u snu, fra Serafin-Bego kad mu je sâm Isus (Isa pejgamber iz Kur'ana, tj. Allahov poslanik, u talmudskim zapisima Ješua, židovski učitelj morala) šanuo da oni Gore ne pitaju ko je koje vjere, nego kakav je po srcu i po duši. Blasfemija? Bogohula? Svetogrđe? Ni-ni, već prava mjera! Amblemske tako - srce i dušu - može iznijeti ma koji vjernik, deist k'o i teist, bogme: i ateist!

\section{Bratimstvo po antimarcijalnosti}

\section{(Arsen Dedić, 1966 : John Lennon, 1971)}

U globalnoetičku tematiku posredno a dično pripada i bard inoga medija našijenac, homo sibeniensis, kantautor Dedić, Arsen, svojom pjesancom (nad pjesancama) za djecu - Kad bi svi ljudi na svijetu... Dakako, silno je to ozbiljna pjesma svojom porukom "na crti" antimarcijalnoga Weltanschauunga, tj. 
proturatničkoga svjetonazora, a time, bogme, irenističkoga (miroljubna) opredjeljenja i ponašanja:

Kad bi svi ljudi na svijetu

Odlučili ruke da spletu

- ne bi tad bilo ni rata.

Gramatika ovakvu složenu rečenicu nazivlje pogodbenom, i to mogućom (s protazom i apodozom, tj. i s glavnom i sporednom rečenicom u glagolskome načinu, ne u vremenu: kad bi... ne bi).

Pretvorbom u nestvarnu (irealnu) rečenicu u protazi je glagolsko vrijeme, u apodozi opet pogodbeni način (kondicional): da su... ne bi:

Da su svi ljudi na svijetu

Odlučili ruke da spletu

- ne bi tad bilo ni rata.

A stvarnu (realnu) inačicu trebalo bi/valjalo, doista i vidjeti i živjeti kao implementaciju, kao ostvaraj globalne etike:

Ako svi ljudi na svijetu

Odluče ruke da spletu

- néce tad biti ni rata.

Očito je: ovdje je i u protazi i u apodozi glagolsko vrijeme: ako (odluče), neće (biti)...

A Dedić je, Arsen to (s)pjevao od 1966!

Duhòvnō i svjetonazorsko (po)bratimstvo između Arsena i Johna očitovalo se kad je Lennon, isto kantautor, od 1971, (s)pjevao svoj čuveni Imagine (= Zamîsli si):

Imagine there's no countries,

Nothing to kill or die for,

Imagine all the people

living life in peace...

Imagine all the people

Sharing all the world...
Zamisli da nema zemalja, Nit ičega zbog čega se ubija il' mre, Zamisli da svi ljudi žive u miru...

Zamisli da svi ljudi

Dijele vascijeli svijet.

A svoju divot-knjigu, remek-djelo (=chef d'œuvre) Deset Besjeda za pomirenje Čovjeka s ljudskošću (Dix Paroles pour réconcilier l'Homme avec l'humain) posvojen (adoptivan) "našijenac". André Chouraqui - kruniše istom inkantancijom: 
Imaginez

un monde sans meurtres sans guerres

un monde sans adultères

un monde sans vols, ni escroquerie, ni corruption.

Un monde sans mensonges, un monde sans jalousie ni convoitises, où chacun serait satisfait de sa part de vie et de bonheur..
Zamislite

svijet bez umorstava

bez ratova

svijet bez preljuba

svijet bez krađa, varanja i korupcije.

Svijet bez laži, svijet bez ljubomore i bez pohlepe u kojem bi svatko bio zadovoljan njemu pripadna života i sreće.

Utopija, dakle: nigdìna?!

Eutopija, dakle: blagdìna!

Kurriozitet: u engleskome leksički par utopia/eutopia, očito, jedva da je heterògraf (= raznòpisnica), no zato je totalan homòfon (= istòzvučnica) u fonetskoj transkripciji na vlas identičan (homofon) : yōōtōpēə; aha : na djelu je lingvistički (d)efekat, mahàna, tj. Mána (što je kao riječ - gle - iransko/perzijska, gotovo da se rekne jezikoslovan "perzijaner", dok u "našeme"/u hrvatskome to je totalan heterògraf, koliko $\mathrm{i}$ heteròfon, a "bokibogme" $\mathrm{i}$ heterònim (= raznòznačnica) : nigdina/blagdina. No nut': dok je nigdina leksikografski registrirana, blagdina nije Te nije, pa ću se pogizditi rezervacijom práva na copy right (tantijeme čekam u kunskoj valuti, tj. pàru po pàru mravljim marom, kàmarēći ( $a$ la turca) stotnìnu po stotnìnu do prve oble kúnē..

\section{Egzilom $\rightarrow \mathrm{u}$ azil?!}

Oklijevam, doista, da li da se opustim/upustim u na pō drzak pokus ( $\neq$ hokus). Pokušao bih da se kolebanjem ne svidim ni sebi samome, a nekmoli komu drugomu. Pa evo - priznajem: iznaprevodio sam se i beletristike i filozofije. No taj "posâl" znao mi bit' i utočište, autoegzil iz pancira, nêgāvā i stegovnosti u struci, ezoterična metajezika u njoj, teorijskih labirinata i zahtjeva sve sofisticiranijih metodologija(h), etc., usw, \& so on. Ipak, dogurah do pred načetak 9. banke, pardon: dekade/decenija IX!

Kad se tako /ovako ispsihoanalizirah - imam stimulativna kredita da i kolegu svećara (da: Damira H.) priupitam - nije li prebrodio il' bar primirisao slična iskustva i ćućenja? Prebjeg iz súhē egzaktnosti u suptilnije i zakučastije temate duhovnosti: problemima o dobru i zlu, akciji i pasivnosti, suprotstavljanja zlu nenasiljem ili silom, rata ili mira... Sva su separirana pitanja bila u knjizi Vladimira Solovjeva: Tri razgovora ili priča o Antikristu, 1900, što ju Damir, Horga, preveo, izdala Detecta, Zagreb 2007. Autor Vladimir Sergejevič Solovjev prijateljevao je s 
biskupom J. Strossmayerom i zagrebačkim kanonikom F. Račkim, suosnivačima JAZU...

Akademski treniran (diplomiran rusist/anglist) uza dinamičnoga, inovatorskoga, čovjekoljubna i energično radišna mentora Petra Guberinu, uzrastao je Damir H. u samostalna znanstvenika. Onom čestitarskom i ujedno častitarskom formulom o hódu kroz(a) pe-m-ziju zazvah kolegi i drugu

... čestit (hôd) kakav mu bio vascijel C. V. s obilom akademskom bibliografijom; no, prije ostalog, kad spelujemo (sričemo/ slikujemo/slovkamo) ono anglo-amerikansko "si"-"vi", tj. drevno ono latinsko curriculum vitae - što praktični Ameri bez iole zazora šifriraju fonetskom si transkripcijom kə-ri-kyə-lam-ve-t $\bar{e}-$ spontano ćemo mu pozavidjeti na strukovnoj alias znanstvenoj koli kàkovosti toli kòlikosti njegova teorijskoga, eksperimentalnog-istraživačkoga, mentorskoga, gastarbajterskoga, gastprofèsorskog kompleksna i u svemu tome postojano sofisticirana fonetičarstva; à ce propos: ispòvjedno, zavist na tuđoj (ma tvoj toj) vrlini/vrsnoći i nije baš velekabast grijeh; dapače: kadra je (takva zavist) obastati kao etički poželjna korektivna stimulacija...

By the way... uz C. V. (onaj istočkast), maločas dešifriran, imade kudikamo kapitalniji bestočkast, grafički čak simbolički zbližen, drugi CV značeći: za medicinare, za pacijente još više: kardiovaskularan, tj. srčàno-krvotočni - recimo: ustroj iliti sustav... a ti se, na "švapsku" - Ojropejče, ili zgražaj il' dívi dovitljivim "kravljim dječacima" alias kaubojzima $=$ cowboys-ima inventivnima $\mathrm{u}$ ekonomičnosti služenja jezičnim abrevijacijama/pokratama.

U drevnoj latinštini gajila se navada da se kojekakve jubilarce-svećare urnebesno dočekivalo il' ispraćalo aklamacijom (tj. burnim klicanjem) il' skandiranjem trojstvenih optativa:

\section{VIVAT - CRESCAT - FLOREAT!}

Ovom zgodom prigodan ovacijski trilling rezerviram Kayu, malomu Amsterdamcu - unuku (pripadna dvojim horizontalnim identičnim trobojnicama: crven/bijel/plavoj naspram identičnoj: rood/wit/blauw) jer njemu je još i te kol'ko živototvòrit' te koli rásti - toli cvjetat/cvasti u dvojim i naizmjeničnim simultanim hodočašćima: majčinskim (Colettinim) nizozemskima ter očinskim (Ognjenovima) hrvatskima... tour-retour Croatia-Nederland... a zaboravljenom srednjoeùropskom / agramerskom titularnom urbanom etikecijom ljupko rečeno - òmami (ómi) Smiljki i òpapi (ópi) Damiru od nadnaslovljena čestitara podjednako dolična, ma i pokratna zdravica: VIVAT! 